\title{
RESENHA
}

\section{NÃO VÃO NOS MATAR AGORA}

\author{
Lucélia Peron ${ }^{1}$ \\ Marlei Dambros ${ }^{2}$
}

O livro "Não vão nos matar agora", escrito por Jota Mombaça e publicado em 2021, convida o leitor a refletir e problematizar questões que estão presentes na sociedade brasileira e em todo o mundo. É o primeiro livro da autora publicado no Brasil e é o primeiro título da coleção chamada Encruzilhada, coordenada por José Fernando Peixoto de Azevedo, que, por meio de diversos autores, vai trazer um debate sobre temas contemporâneos como antirracismo, feminismo e anticolonialismo.

Jota Mombaça é uma jovem de 20 anos que nasceu em Natal - RN e, atualmente, trabalha e vive entre Fortaleza, Lisboa e Berlim. É uma artista e escritora brasileira que trabalha com poesia, teoria crítica e performance. Faz estudos acadêmicos em torno das teorias sobre gênero, giro decolonial, justiça anticolonial, redistribuição da violência, ficção visionária e produções de conhecimentos do sul-do-sul globalizado. Seus trabalhos abordam, especialmente, temas como as relações entre monstruosidade e humanidade, crítica colonial e tensões entre ética, estética, arte e política nas produções de conhecimentos.

A partir da coletânea de textos que compõe a obra, apresenta críticas ao modo de atualização da violência sistêmica da branquitude e do fundamentalismo cisgênero, e aponta horizontes que vislumbram a importância de existir em meio às feridas deixadas pelo colonialismo. Além disso, busca repensar o mundo como o conhecemos, afirmando a potência de corpos e "corpas" que resistem às adversidades e às violências de um sistema de controle que tenta inutilmente rotulá-los, negá-los e capturá-los, propondo alternativas para que aconteçam transformações rumo ao novo.

\footnotetext{
${ }^{1}$ Doutoranda em Educação Científica e Tecnológica pela Universidade Federal de Santa Catarina (UFSC). Técnica em Assuntos Educacionais na Universidade Federal da Fronteira Sul - UFFS. E-mail: luc.peron@gmail.com. Orcid: https://orcid.org/0000-0002-3112-9064.

${ }^{2}$ Doutoranda em Educação Científica e Tecnológica pela Universidade Federal de Santa Catarina (UFSC). Pedagoga na Universidade Federal da Fronteira Sul - UFFS. E-mail: marlei.dambros@uffs.edu.br. Orcid: https://orcid.org/0000-0003-3382-9504.
}

Revista de Estudos em Educação e Diversidade. v. 2, n. 6, p. 1-6, out./dez. 2021. Disponível em: http://periodicos2.uesb.br/index.php/reed

ISSN: 2675-6889 
No livro, o leitor vai encontrar uma ordem decrescente da numeração dos capítulos que o compõe. Inicia pelo capítulo 1 , depois o capítulo 0 , o -1, o -2, até o -9, quebrando um tempo linear e propondo um contratempo. Com esse tempo decrescente, quer transmitir-se a ideia de quebra, destruição, demolição de uma série de modos impostos de como lidar com as coisas, incluindo o tempo. A intenção é experimentar outras possibilidades do tempo, outros modos de temporalidade e criar resistência contra a lógica do tempo linear que envolve nossas vidas e construir outras possibilidades de olhar, de escutar e de existir.

No primeiro texto, denominado "Carta às que vivem e vibra apesar do Brasil”, a autora destaca que o livro "foi feito como uma barricada" (p.17), pois é uma compilação de críticas às violências sistêmicas da branquitude, observadas a partir da própria experiência de ocupar um corpo classificado como transexual, pardo e marcado pelas memórias indígenas. Essa posição permitiu-lhe vivenciar um sistema que discursa sobre justiça e descolonização, mas que na prática, segue reproduzindo comportamentos violentos contra negros, indígenas e trans.

O capítulo 1 é escrito na tentativa de destacar as forças que surgem de dentro para fora e quebram os ideais normativos de gênero, sujeito e coletividade. Aqui, algumas das questões apresentadas são: e se, em vez da inteireza, da autoconsciência, da autodeterminação e da autoestima houvesse um sentido de "quebra", que desloca efetivamente as posições inconformes à matriz cisgênera? E se esse modo de ser, quebrado demais para traduzir-se em uma coerência identitária e representativa, insinuasse uma forma de presença efetivamente desobediente de gênero? Como habitar uma vulnerabilidade e como engendrar, nesse espaço tenso das vidas quebradas pela violência normalizadora, uma conexão afetiva de outro tipo, uma conexão que não seja baseada na integridade do sujeito, mas na sua incontornável quebra? Mombaça também destaca que a definição de "quebra" pode ser entendida como o que não se define, como um movimento abrupto e desordenado, como o que acontece quando uma vidraça arrebenta e que essas reflexões fortalecem o sentido que acompanha o movimento de enfrentar o mundo e viver a vida.

No capítulo 0, intitulado "O mundo é meu trauma", apresenta um instigante texto que provoca muitas inquietações sobre questões fortes e doloridas. Mombaça é contundente quando aborda questões sobre o terror, as dores, as lutas, as violências e agressões que os diferentes corpos sofrem e propõe que a partir dos traumas, das ansiedades, dos desânimos, da pressa e da esperança no futuro, se possa sair da posição de um sobrevivente para uma condição de existente e, assim, vencer a batalha contra o mundo.

Revista de Estudos em Educação e Diversidade. v. 2, n. 6, p. 1-6, out./dez. 2021. Disponível em: http://periodicos2.uesb.br/index.php/reed

ISSN: $2675-6889$ 
“A coisa tá branca!" é o capítulo -1. A intenção é questionar os limites da apropriação branca dos discursos e práticas antirracistas e descoloniais, evidenciando o modo como elas tendem a operar e continuar representando a dominância e o protagonismo social. A autora destaca que é importante e necessário a colaboração das pessoas brancas e historicamente privilegiadas pela colonialidade com as lutas antirracista e anticolonial. Contudo, não basta realizar discursos que pretendem desafiar o racismo. É necessário que o trabalho seja feito na própria infraestrutura de privilégios, ou seja, todos os processos que dão suporte à vida branca como norma social devem ser postos em xeque pelas próprias pessoas brancas. Num contexto onde a presença não hegemônica está marcada pela exclusão e pela exploração, não é suficiente que as pessoas em situação de privilégios social, ontológico e epistêmico aprendam a falar a linguagem do antirracismo e da descolonialidade. O trabalho necessário é o de reposicionar os corpos, as subjetividades e as vidas subalternizadas na dinâmica de vida do mundo branco para destruir um sistema no qual as vidas negras só importam à medida em que são produtivas.

No capítulo -2, Mombaça esclarece que o texto é escrito pela trabalhadora cultural transexual e negra, sendo esta a forma que a autora se apresenta. Ela almeja abordar como os modos contemporâneos de mercantilização exploram os corpos transexuais pretos e indígenas dentro do mundo da arte. O texto afirma que o sistema de arte contemporâneo é um dispositivo voltado ao consumismo branco e cisgênero e à exploração do outro, já que, em cenários artísticos hegemônicos, o trabalho transexual racializado cria imagens, textos e ideais para o consumo de audiências brancas e é apropriado por instituições como uma evidência de responsabilidade social, diversidade e inclusão.

"Rumo a uma redistribuição desobediente de gênero e anticolonial da violência" é o capítulo -3 da obra. Nele, por meio de sete cenas que retratam diferentes tipos de violências, a autora faz uma crítica às estatísticas e atitudes de agressões contra negros, mulheres, transexuais, pobres e também aponta importantes e profundas reflexões sobre como a polícia e o Estado operam para garantir a segurança das elites brancas, destacando que esse modo de atuar faz parte de um projeto de poder que se ampara no desejo de operar fora dos limites da lei. Mombaça faz uma denúncia de como o poder opera, se prolifera e continua materializando crimes, racismo, processos de exclusão, violência e brutalidades. A partir desse cenário, propõe uma redistribuição da violência como um gesto de confronto e de autocuidado, mas também como um projeto de justiça social que deve ser concebido por todas as pessoas para quem a paz nunca foi uma opção.

Revista de Estudos em Educação e Diversidade. v. 2, n. 6, p. 1-6, out./dez. 2021. Disponível em: http://periodicos2.uesb.br/index.php/reed

ISSN: 2675-6889 
Na sequência, o capítulo -4 apresenta notas sobre as estratégias dos usos políticos do conceito de "lugar de fala", que tem o objetivo de dar oportunidade para que se fale das posições e marcas políticas que um determinado corpo ocupa nesse mundo, que é organizado por formas desiguais de distribuição das violências e dos acessos. Ou seja, o conceito da expressão é uma ferramenta de interrupção de vozes hegemônicas para dar possibilidade de emergência de vozes historicamente interrompidas e com isso desestruturar os modos de violência e marcar o não marcado.

A autora segue com o capítulo -5, onde apresenta um exercício de escuta, um trabalho sobre as tendências da política contemporânea, sobre os modos de atualização do genocídio negro ao longo da história moderno-colonial, mas também sobre a dimensão espiritual das forças e fragilidades integradas. É também um exercício comprometido com o futuro imediato de estudar o terror e conceber formas coletivas de enfrentá-lo. Mostra que "veio o tempo em que por todos os lados as luzes desta época foram acendidas" (p. 91), ou seja, chegou o tempo em que não há mais como negar que os diferentes corpos e as vidas negras estão e sempre estiveram aqui. É a hora de "perturbar a paz que nos soterra, invadir a consciência pacificada daqueles que vivem acima de nós e estremecê-la com a dor que somos feitas" (p. 96). Além disso, "desejamos profundamente que o mundo como nos foi dado acabe". (p.100)

Indo a frente, no capítulo -6, há uma descrição do espetáculo solo NoirBLUE da bailarina, investigadora, coreógrafa e artista da imagem Ana Pi. Relata que, nas suas práticas, Ana Pi aborda as tradições incorporadas da diáspora negra e as danças contemporâneas periféricas, em um movimento voltado à invenção de exercícios de liberdade transitórios, de micro e múltiplas interrupções nas coreografias normalizadas de captura e violência, de gestos comprometidos com o ato de luta continuada para que as vidas negras importem.

Mais adiante, o capítulo -7 é dedicado a apresentar reflexões sobre o que o estudo significa para a fuga. Diz que estudar é importante "para fugir, para habitar o desterro, a catástrofe e os outros mundos possíveis que se precipitam ao fim deste" (p.109). Esclarece que por meio da dor das violências e dos traumas, ainda que sufocantes, existem possibilidades de estudo e de aprendizagem para a construção de um novo futuro, que existe para ser maleável e, portanto, moldado. Aposta nos livros como um caminho para aprender coisas que possam ajudar a vencer o medo, a lidar com as realidades, a crueldade, a miséria, os desencantos e, com isso, superar e transcender o que não se pode aceitar para sempre aqui. 
Seguindo, no capítulo -8, que é em forma de carta, está destacada a crueldade que a história tem exigido e afirma que não se pode ser ingênuo perante as formas de poder, pois "não se sobrevive a uma guerra fingindo simplesmente que os canhões não estão apontados, que não há arame farpado nas ruas e que os cães de guarda não enxergam sua mira em nosso pescoço" (p. 113). Ressalta que é preciso ficar atento com as coisas e as pessoas que nos cercam e ter força para visualizar as máscaras do mundo e acreditar que uma semente irá florescer.

“O nascimento de Urana” é o capítulo -9. Nele, os leitores são convidados a interagir com um episódio imaginativo que tem a pretensão de contribuir para a construção de estratégias coletivas de resistência, luta e contraposição aos modos de violência que atingem corporalidades transexuais, ou seja, é um convite para potencializar outras formas de existência e coletividade.

A obra é finalizada com um texto escrito por Cíntia Guedes. Para ela, cada texto que compõe o livro busca provocar transformações e convocar as pessoas a participarem desse movimento. Além disso, também destaca que os escritos não têm a intenção de simplesmente ensinar alguma coisa, mas, trata-se sim, de um livro com dimensões políticas, que articula movimentos teóricos e poéticos para escrever sobre a não humanidade e os projetos românticos de libertação, que sustentam as mesmas lógicas de dominação historicamente existentes e que colabora para alterar posições, paradigmas e desperta sensibilidades.

A obra é destinada a todas as pessoas que têm interesse na temática e que provoca o presente buscando lançar olhares sobre como a violência normalizadora, as injustiças, a exclusão e a opressão têm atuado ao longo do tempo, apontando horizontes para enfrentar, romper e transformar esses processos e a percepção histórica construída sobre os corpos negros, indígenas, transexuais, migrantes etc.

Evidenciando os movimentos da vida a partir das marcas do desconforto e da dor, Mombaça incentiva esse coletivo a estar presente em diferentes espaços, a avançar sobre caminhos instáveis, a agir politicamente e conduzir o debate antirracista e descolonial. Destaca que é preciso um trabalho coletivo para acabar com o binário subalternidade-dominância e reposicionar os corpos e vidas na estrutura social e por fim no sistema desigual de distribuição de recursos. A obra tensiona o processo histórico que segue reproduzindo as injustiças que matam e aprisionam, e convida a todos a pensar em possibilidades e alternativas para se viver de modo diferente.

Revista de Estudos em Educação e Diversidade. v. 2, n. 6, p. 1-6, out./dez. 2021. 


\section{Revista de Estudos em Educação e Diversidade}

\section{Referência}

MOMBAÇA, Jota. Não vão nos matar agora. Rio de Janeiro: Cobogó, 2021.

Recebido em: 01 de outubro de 2021.

Aprovado em: 19 de dezembro de 2021.

Revista de Estudos em Educação e Diversidade. v. 2, n. 6, p. 1-6, out./dez. 2021. Disponível em: http://periodicos2.uesb.br/index.php/reed 